\title{
Stomatological problems and infectious complications after hematopoietic stem cell transplantation
}

\author{
Artur P. Grigoriants ${ }^{1}$, Ilya M. Rabinowitch ${ }^{2}$, Alexey B. Chukhlovin ${ }^{1}$ \\ ${ }^{1}$ The First St. Petersburg State I. Pavlov Medical University, St. Petersburg, Russia \\ ${ }^{2}$ Central Research Institute of Stomatology, Moscow, Russia
}

Dr. Artur P. Grigoriants, Associate Professor, Department of Propedeutic Dentistry, The First St. Petersburg State I. Pavlov Medical University, L. Tolstoy St. 6-8, 197022, St. Petersburg, Russia

\section{Summary}

The review article deals with early and late oral and dental problems occurring after intensive anticancer chemoand radiotherapy and hematopoietic stem cell transplantation (HSCT). High-dose cytoreductive therapy may be accompanied by long-term cytopenia followed by slow recovery of myelo- and lymphopoiesis; complications of immunosuppressive treatment due to graft-versus-host disease (GVHD). I.e., post-transplant immune pathology is accompanied by high risk of dental infections thus requiring prophylactic caries treatment, and antiseptic regimens in cytopenic period. The therapy-associated affection of oral epithelial cells leads to early mucositis and aggravates acute graft-versus-host disease. Autoimmune-like complications (atrophy of oral epithelium and salivary glands, dry mouth syndrome) are frequently observed within several months after allogeneic HSCT. In pediatric patients, massive chemotherapy and radiation treatment is followed by stunted root growth, lagging primary dentition, hypoplasia of tooth enamel etc. In adults, cytostatic chemotherapy causes more intensive oral infections. Differential protocols are proposed for children and adults in order to perform prophylaxis and treatment of dental pathology in the patients undergoing auto- and allo-HSCT. The gastrointestinal mucosa is an important part of the immune system and there is a delicate equilibrium between the flora itself and the immune surveillance by the host's immune system. There is a good evidence that the mucosal immune system plays a pivotal role in the development of the patient's immunity against food antigens and microbial antigens thereby distinguishing between reaction and tolerance.
Phone: +7(921) 9075545

E-mail: grigoryants.1961@mail.ru
Viral infections are known to pave the way for subsequent fungal and bacterial infections, but complex interactions between the viruses, bacteria, fungi, nematodes and host mucosa may complicate the picture. A still largely unknown but highly important mechanism of transkingdom control may be associated with poorly studied role of phages that may modulate bacterial colonization. These interactions may be complicated by clinically applied antibiotics (absorbable and non-absorbable), antivirals and other drugs.

There are also some encouraging new ways to prevent and to treat GVHD. Moreover, one may select donors according to their immune repertoire and genetic background for $\mathrm{T}$ cell activation. Possibly this can be combined with an anti-leukemic efficiency based on anti-microbial activity and HLA class II DP histocompatibility. In general, the immune activation may be important that is induced by the actual microbiome and determined genetically by the donor and the host.

\section{Keywords}

Hematopoietic stem cell transplantation, immunosuppressive treatment, oral epithelium, immune-mediated disorders, dental infections, treatment, prophylaxis. 


\section{Introduction}

Over last years, a number of effective protocols has been developed for treatment of oncohematological diseases (leukemias and lymphomas) based on application of cytoreductive chemo- or radiation therapy. These treatment protocols, along with novel targeted drugs, bring about long-term remissions in these patients. However, quality of life in these patients is often disturbed, due to serious complications affecting different organs and systems. Dental complications, such as infectious and atrophy of oral mucosa and teeth occur quite often when treating oncological patients, especially children after chemo- or radiation treatment of leukemias and other malignancies $[1,2,3,4]$. Treatment protocols in oncohematology usually include several rounds of cytoreductive therapy. Cytotoxic drugs or radiation treatment affect sensitive cells, both malignant and normal ones. Due to heavy insult to hematopoietic system, the leukocyte numbers begin to drop since day 5-6 after starting cytotoxic therapy cycle and recovers only at 2-3 weeks when the next round of therapy could be performed.

Quite intensive cytoreductive therapy, the so-called conditioning treatment, is administered before hematopoietic stem cell transplantation (HSCT) which causes a very deep suppression of hematopoiesis with entire depletion of granulocytes and most lymphoid cell population in peripheral blood, bone marrow and lymphoid organs. Their recovery occurs within weeks and months [5]. Along with blood cells, the cytoreductive treatment causes massive death of epithelial stem cells in oral cavity, intestines, lungs, urogenital tract etc. The therapy-induced epithelial damage manifests by early mucosites, colitis and other organ-specific syndromes. Intensive death of normal cells due to cytoreductive treatment followed by HSCT is, therefore, connected with repeated rounds of chemo-and radiation therapy which lead to maximal cytoreduction in epithelial organs as well.

The most common oral complications and main guidelines for managing dental disorders in the patients undergoing chemo/radiation therapy in children are well described in appropriate recommendations issued by American Academy of Pediatric Dentistry [6]. One should be noted that, by the time of HSCT, the patients already have marked immune deficiency cuased by previous courses of cytostatic therapy. Such immunocompromising condtions require all preventive dental programs to be performed before starting intensive anticancer treatment with following HSCT. If it is not possible, some provisional dental procedures are performed that should be continued upon stabilization of hematological and immune state of the patient. Over the period of post-transplant cytopenia, immune deficiency and concomitant oral complications, only local treatment is performed which is aimed for cytoprotection and accelerated healing of oral mucosae.

Hence, the aim of this review article was the discussion of epidemiology, pathogenesis, prevention and treatment of oral complications following intensive cytostatic therapy and hematopoietic stem cell transplantation. Disorders of oral mucosa represent several pathogenetic phases, from early toxic mucositis to late immune-induced atrophy of mucosal structures and salivary glands. Their treatment requires special approaches at every time period post-transplant

\section{Conditioning- and time-dependent features of oral complications in HSCT-procedure}

Classical protocol for hematopoietic stem cell transplantation (HSCT) includes intensive chemo and/or radiation therapy (either myeloablative, or reduced conditioning regimens) delivered over limited terms (several days), thus causing a subsequent prolonged immune suppression. Such temporary immune deficiency is determined by several cytotoxic factors, i.e.:

1) High-dose cytoreductive therapy;

2) Long-term recovery of myelo- and lymphopoiesis posttransplant;

3) Antibacterial and antiviral treatment;

4) Acute graft-versus-host disease (aGVHD);

5) Long-term immunosuppressive therapy

(Cyclosporin etc.);

6) Chronic GVHD

Time course of bacterial and viral complications observed after intensive chemotherapy and hematopoietic stem cell transplantation is well presented in appropriate reviews [7, 8]. The dental and mucosal complications are dependent on distinct time periods of conditioning therapy and subsequent transplantation [6]:

\section{Phase I: Dental care before conditioning therapy}

At this stage, oral complications are determined by the patient's age, his/her general condition and oral health. In cases of hematological malignancies, the risk of posttransplant disorders depends on extent of local oral pathology, total intensity of previous cytoreductive therapy. Oral pathology at the pre-transplant stage may include oral infections, gingival leukemic infiltration, ulcers, bleeding, temporo-mandibular dysfunction.

Most principles of dental care before HSCT are similar to those applied to children suffering with malignancies. The two main differences are as follows: 1) in HSCT, the patient receives entire course of chemo- or radiation therapy several days before transplant; 2) HSCT is accompanied by a longterm immune suppression. Therefore, any elective dental care should be postponed until the immune restoration, i.e., at least 100 days after HSCT and even later, in cases of severe chronic GVHD or other complications. Vice versa, all urgent dental treatment should be completed before development of immune suppression in the patient.

\section{Phase II: Neutropenic period following HSCT}

The major oral complications at this time period, from the patient admission to HSCT clinic, and up to day +30 post-transplant, are caused by the cytostatic treatment and supporting therapy. They include oral mucositis, xerostomia, local pain, hemorrhages, taste anomalies, neurotoxicity (toothache, muscle tremor, temporo-mandibular pain, head- 
ache etc.) may be registered, associated with common oral infections.

Oral mucositis develops within 7 to 10 days after starting of intensive treatment, and its symptoms are traceable for ca. 2 weeks after its completion. The patients should be observed thoroughly, and their oral condition should be traced. Optimal oral care is of crucial importance at this stage. Any kind of dental treatment should be avoided, due to severe immune suppression in the patient over this time period. Urgent dental interventions should be performed in close co-ordination with attending oncohematologists.

\section{Phase III: Engraftment and recovery of hematopoiesis}

Severity of the oral symptoms decreases by 3 to 4 weeks posttransplant, with domination of fungal invasion and herpes simplex infection. The infections are often combined with acute graft-versus-host disease, which may present sufficient problems after allogeneic HSCT. Differential histopathological features of oral infections and aGVHD should be considered. I.e., sometimes, one may observe xerostomia, hemorrhages, neurotoxicity, temporo-mandibular dysfunction, granulomas, papillomas etc. Examination of oral cavity and teeth as well as invasive stomatological procedures, e.g., tooth cleaning and soft tissue curettage should be agreed with transplantation team, due to continuous immune suppression in the patients. They should be encouraged to optimize their dental hygiene and avoid caryogenic diet, also being alert for xerostomia ("dry mouth") and oral GVHD signs. For unclear reasons, oral cavity in transplanted patients shows increased temperature sensitivity for 2 to 4 months after HSCT. Local application of neutral fluoride or desensitizing tooth pastes may alleviate these symptoms.

\section{Phase IV: Long-term restoration of immunity after systemic cytotoxic treatment}

At later terms (over 100 days post-transplant), most oral complications are caused by chronic effects of preceding cytostatic therapy, including dysfunction of salivary glands, chronic GVHD affecting oral mucosa, as well as late viral infections. Oral squamous cell carcinoma may develop in oral cavity, like as other secondary malignancies. Relapse of the disease may be associated with xerostomia and injuries of oral cavity. However, late bacterial infections are less common, despite common neutropenia or severe chronic GVHD in the patients. Occasional dental examination with X-ray studies could be performed. Invasive dental care should be avoided in immunocompromised patients. Orthodontic care should be consulted with attending doctor and relatives of the patient, concerning risks and benefits of such treatment.

\section{Phase V: Long-term survival following HSCT}

Problems with development of orofacial, skeletal structures or teeth have similar origin for any complications observed in children who survived treatment of malignant diseases. In children, delayed growth of jaws and skull bones is observed months and years after intensive chemo-and radiotherapy. Such problems, generally, manifest in children under 6 years old and occur due to osteoblast suppression caused by prolonged cytostatic therapy. Long-term effects of the anticancer treatment may also include dental agenesis, microdontia, altered size and form of teeth, hypoplastic enamel, malforma- tions of pulp cavity and dental roots as well as underdevelopment of jaws. Severity of such anomalies will depend on the patients' age at the time of cytotoxic treatment. The patients may suffer of permanent dysfunction of salivary glands or xerostomia. Moreover, relapses of primary malignancies, or secondary cancer may also develop several years later.

Hence, the cancer survivors, especially younger patients, need routine dental examination and optimal oral care. The attending dentist should perform regular careful inspection of teeth, gingivae, tongue and oral mucosae, as well as adjacent areas. X ray studies and accessory cytological diagnostics should be performed in order to detect any head and neck malignancy. Dental treatment in such cohort needs a multidisciplinary approach with cooperation of different dental specialists in order to administer optimal treatment for any distinct case. Steady contact and consulting with attending oncologists is required, especially in case of relapse or immune deficiency suspected in the patient.

Most pathological changes of oral mucosae and epithelium (mucositis, gVHD, infections, later chronic complications) are accompanied by inflammation of mucosae and salivary glands. Role and pathogenetic mechanisms of inflammatory events are discussed, e.g., by Havermann et al. [9].

According to Fabuel et al. [10], the most common early oral complications in HSCT patients are as follows:

1. Acute mucositis caused by direct toxic action upon progenitor epithelial and bone cells of oral cavity. WHO classification distinguishes 5 grades of mucositis, from mild erythema to severe ulceration of oral mucosa. This pathology is associated with xerostomia, viscous saliva, intensive pain syndrome when eating, drinking or swallowing. Oral mucositis becomes clinically sound soon after HSCT reaching its maximum 5 to 7 days post-transplant and fades away gradually, within 2-3 weeks after HSCT. Focal necrosis of mucosae and labial skin is observed. In addition, caries new caries lesions may occur. For practical purposes, three stages of posttransplant oral mucositis are distinguished, depending on severity of mucositis, local pains and feeding difficulties [11].

2. Infectious complications mostly manifest as stomatitis caused by pathogenic bacteria, viruses or fungi.

3. Oral bleedings may occur in the patients due to suppression of hematopoiesis and thrombocytopenia, as well as primary disorder (e.g., acute leukemia).

4. Acute graft-versus-host disease (aGVHD) is observed within 100 days post-HSCT being a pathological immune reaction induced by the donor autoaggressive lymphocytes against some recipient antigens. aGVHD proceeds as a systemic inflammatory response involving cytokine activation. aGVHD affects mostly epithelial cell populations, including oral epithelium, thus representing a leading factor of severe complications and mortality among HSCT patients. Oral aGVHD presents as xerostomia, erythema, lichenoids, papular lesions, atrophy, and ulceration of mucosal surfaces. 


\section{Stepwise development of oral histopathology after conditioning therapy and hematopoietic trans- plantation}

The first step of cytotoxic lesion, oral mucositis (OM) is a serious complication which depends on the total dose of chemotherapy and types of cytostatic drugs. E.g., Chaudhry et al. [12] have performed a systematic review on the incidence and outcomes of OM in allogeneic HSCT patients and their occurrence at various conditioning regimens. Grade of $\mathrm{OM}$ was analyzed based on the standard WHO Criteria for Adverse Events scales. Severe mucositis was defined as grades 2-3-4. A total of 624 studies were taken for analysis. In general, $73 \%$ experienced any signs of OM, whereas severe (grades 2 to 4 ) OM occurred among $79.7 \%$ of the WHO/NCI-graded MA patients and $71.5 \%$ after reduced-intensity-conditioning. In comparing graft-versus-host disease (GVHD) prophylaxis, the non-methotrexate regimens caused $\mathrm{OM}$ in $55.4 \%$, thus being lower than among patients who received methotrexate $(83.4 \%)$.

Primary insult to oral mucosa induced by intensive cytostatic treatment was described as early as in 1988 [13]. The workers analyzed early oral changes after HSCT. These changes included altered mucosal color (white and red) with subsequent atrophy, ulceration, accompanied by more viscous saliva, hyposecretion of salivary glands, causing xerostomia. This pathology determines subjective complaints of oral pain and dryness. The histological and clinical changes were most evident at ventral tongue, buccal and labial mucosa, and marginal gingival beginning just after conditioning treatment, peaking at 2 weeks after HSCT with following gradual mucosal repair. This complex pathology occurs due to conditioning chemoradiotherapy, immunosuppression after HSCT, occasional traumas posttransplant immunosuppressive chemotherapy, as well as due to activationg infections (mostly viral activation) local trauma, oral infections (especially those caused by HSV), and possibly acute GVHD. The viral and GVHD mechanisms should be considered in cases of worsening oral lesions at 3 weeks or later post-transplant.

These pathological findings were supported by several other studies [14]. A group of 54 children with oncohematological disorders were subjected to allo-HSCT, with $62 \%$ exhibiting clinical oral side effects upon treatment. These lesions were observed over first 2 weeks after conditioning therapy, transplantation, and until engraftment of the donor marrow having been ascribed to preceding chemo- and radiotherapy. Oral ulcers were seen in $34 \%$ of the cases. Administration of methotrexate for GVHD prophylaxis seemed to cause more common oral ulcerations rather than cyclosporin. HSV reactivation was observed in $35 \%$ of the children who were seropositive prior to BMT. Oral candidiasis was also a common finding (15\% of the patients).

\section{Early infections and inflammatory conditions of oral cavity following HSCT}

Clinical infections of teeth and oral mucosa are widely spread in general population. E.g., colonization with Streptococcus mutans and parodonthogenic bacteria is revealed in gingival mucosa and dental plaque since pre-school age, becoming more common in later life [15]. The long-term immune deficiency after cytostatic chemo- and radiation therapy is widely known to promote a more active growth of odontogenic microflora. Incidence of oral HSCT complications was summarized using databases of the USA transplantation centers from 2004 to 2010 [16]. Over this time period, HSCT was performed in 101462 patients. Gingivitis or periodontitis was diagnosed in only $0.22 \%$ of the cases. Such low incidence, when compared to general population, may be connected with optimal dental care and full mouth debridement carried out before HSCT. Meanwhile, this study shows that gingival and periodontal problems in HSCT patients implies higher treatment costs, longer hospitalization period, and increased risks of infectious complications. E.g., septicemia, bacterial infections and mycoses in the patients with periodontitis were observed significantly more often than in cases without gingival problems before HSCT.

Several studies from 90's support a defnite role of human herpesvirus type 6 (HHV6) in oral pathology occurring after HSCT [17]. This study was performed using a golden standard, the virus isolation, in 15 allogeneic and 11 autologous marrow transplantation patients. HHV6 type B was isolated posttransplant from peripheral blood mononuclears of 12 of 26 patients. Interestingly, 11 of 26 and 12 of 19 patients showed salivary shedding of HHV-6 DNA both before and after transplantation. In sum, 23 of 26 patients showed evidence of active HHV-6 infection either by the virus isolation, salivary shedding, or increased antibody titers. Active human cytomegalovirus infection was associated with HHV-6 isolation, as also confirmed in later studies. However, no association was observed between HHV-6 infection and GVHD, pneumonia, delay in engraftment, or marrow suppression in this study. The initial results of HHV6 studies were confirmed by Cone et al. [18].

\section{Oral immune pathology in chronic GVHD}

Histological changes observed at later stages post-HSCT, the s.c. chronic GVHD, seems to be of mostly autoimmune origin, due to cytotoxic damage of vascular structures and mucosal epithelium induced by donor effector cells. In cases of chronic GVHD, the changes in oral mucosa developing 12 months or later after transplantation comprise erythema of mucous membranes, tongue atrophy and also lichenoid changes in the buccal mucosa [14]. The study by Motta to al. [19] was performed in 12 patients undergoing allo-HSCT. The paired oral cGVHD biopsies obtained before and 1 month after treatment with topical dexamethasone $(n=8)$, or tacrolimus $(n=4)$ were subjected to immunohistochemistry 
of main immune markers (CD1a, CD3, CD4, CD8, CD20, CD31, CD62E, CD103, CD163, c-kit, and FoxP3) as compared to bioptates from aGVHD, oral lichen planus, and normal tissues. The oral bioptates in CGVHD were characterized by basal cell squamatization, lichenoid inflammation, sclerosis, apoptosis, and lymphocytic exocytosis. The infiltrating immune cells in oral cGVHD primarily consisted of $\mathrm{CD}^{+}, \mathrm{CD}^{+}, \mathrm{CD}^{+}, \mathrm{CD} 103^{+}, \mathrm{CD} 163^{+}$, and $\mathrm{FoxP}^{+}$ cells, exceeding the levels of normal tissues thus presuming a largely T-cell-driven inflammation with macrophage participation. Topical dexamethasone or tacrolimus reduced the mentioned cell pathology in oral cGVHD, while reducing the number of $\mathrm{CD} 4^{+}$and $\mathrm{CD} 103^{+}$cells.

Clinical signs of chronic oral GVHD develop at later terms post-transplant ( $>100$ days after HSCT), being observed in $50-80 \%$ of total cases. The cGVHD symptoms include erythema, atrophy of the tongue surfaces, lichenoid changes of buccal mucosae accompanied by ulcers and increased oral cancer risk [10]. Salivary gland dysfunction causes xerostomia, clinical pattern of parotitis, excess of mucous substances and lower saliva production. These symptoms may persist, at least, for 1 year after HSCT.

The cGVHD, like as acute GVHD, develops by immune mechanisms. It affects different organs and tissues including oral cavity. Clinical pattern of oral cGVHD, generally, is similar to the Sjogren disease, a well-known autoimmune disorder [20].

So far, there are no validated cGVHD biomarkers correlating with clinical except of relatively unspecific parameters, e.g., altered albumin or high complement levels [21]. Increased albumin, $\mathrm{Na}^{+}, \mathrm{Cl}^{-}$concentrations, changes of lactoferrin an protease inhibitors may be observed in oral fluid of the cGVHD patients [22].

\section{Treatment of early post-transplant oral disorders (mucositis and aGVHD)}

Oral mucositis, being a very common complication of intensive chemotherapy followed by HSCT occurring in ca.70$80 \%$ of the cases, thus needing novel management strategies which include both preventive measures and therapeutic approaches. Pathophysiology of acute oral includes complex interactions between the products of tissue damage, reactive oxygen species, local microbiota and host immune system, which determines the grade of inflammatory response in oral mucosa and salivary glands. Genetic factors plays a major role in the development of this toxicity [23]. Although only few therapeutic agents are available, several promising drugs are under clinical trials.

Palifermin (keratinocyte growth factor) is the only pharmacological drug approved by the European Medicines Agency and the US Food and Drug Administration (FDA) for mucositis. Palifermin is administered intravenously prior to the initiation of chemotherapy and for an additional 3 days beginning since the day of HSCT [24].
Pathogenetic treatment also includes a number of anti-inflammatory drugs, either cytokine-based therapy, or non-steroid anti-inflammatory drugs, pentoxifylline etc. [23]. Biological cell-containing preparations are also tried to this purpose. Recently, Piccin et al. [25] has reported a lymphoma patient with severe oral and esophageal mucositis developed after high-dose chemotherapy, auto-HSCT, severe sepsis, viral infection and neutropenia. Platelet gel from cord blood was topically administered daily to the oral cavity. After 8 consecutive days, full recovery of mucositis was seen without any side effects. Therefore, controlled studies are required to compare efficacy of autologous and allogeneic platelet gels in severe mucositis.

A study in pediatric patients has also shown some efficiency of low-level laser therapy (LLT) in oral mucositis [26]. The authors have developed a specialized oral care protocol that included LLT for pediatric HSCT patients. Data from OM-related morbidity were collected from 51 HSCT pediatric patients treated daily with LLT, followed by standard oral care protocols. All the patients, even at younger ages, tolerated the LLT therapy well. The maximum OM degree was WHO II. Patients after autologous and HLA-haploidentical transplants showed less severe OM, and better clinical outcomes are reported with LLT which could be included into the specialized oral care in this cohort of children.

\section{Novel treatments of mucosal aGVHD}

Oral immune-like syndromes are sometimes observed in acute GVHD after HSCT. E.g., Ion et al. [27] has studied twenty-one such GVHD cases of which 5 demonstrated only oral features; the remaining 16 had variable involvement of skin $(n=14)$, liver $(n=7)$, and gut $(n=5)$. The median time for onset of oral aGVHD was 35 days (11 to 159 days). The sites affected by nonspecific erythema and ulcerations included buccal mucosa (19 of 21) tongue (18 of 21 dorsum in 8), labial mucosa (16 of 21, palatal mucosa (15 of 21; hard palate in 7 ), and floor of mouth (7 of 21). Eight cases (38\%) presented with lip ulceration and crusting. In addition to systemic therapies, topical solutions of dexamethasone, tacrolimus, and morphine were used for additional support. Oral features of aGVHD may be the initial manifestation and include nonspecific erythema and ulcerations of keratinized and nonkeratinized mucosa and lips. Intensive topical therapies may help reduce symptoms and promote healing.

Previous successful experience with blood platelet gels was based on regenerative effects upon diabetic or surgical wounds, due to local release of growth factors such as fibroblast - derived growth factor, platelet-derived growth factor etc. [28]. Their study was aimed for assessing efficacy and safety of allogeneic platelet gel for treating ulcers in the skin or oral aGVHD. Platelet-rich fibrin was obtained by automated process (Vivostat system, Vivostat A/S). Six patients with multiple lesions involving dermis (Grade $I, n=2$ ), subcutaneous (Grade II, $\mathrm{n}=4$ ), or oral mucosa related to GVHD were administered the gel as local therapy. After the second gel application, the pain faded away, and granulation tissue was observed in four cases with Grade II lesions. After a me- 
dian of eight PLT gel applications (range, 4-10), five of six patients showed a complete response, without any side effects documented.

Pharmacological agents to target mucosal barrier dysfunction in GVHD are needed. Induction of Wnt signaling by lithium, an inhibitor of glycogen synthase kinase (GSK3), was suggested to potentiate intestinal crypt proliferation and mucosal repair [29]. A pilot study included 20 patients with steroid refractory intestinal GVHD who were given oral lithium carbonate against a group treated with glucocorticoids. As a result, 8 of 12 patients (67\%) had a complete remission (CR) of GVHD and survived more than 1 year (median 5 years) when lithium administration was started promptly within 3 days of endoscopic diagnosis of denuded mucosa. When lithium was started promptly and less than 7 days from salvage therapy for refractory GVHD, 8 of 10 patients $(80 \%)$ had a CR and survived more than 1 year. Toxicities included fatigue, somnolence, confusion or blunted affect in $50 \%$ of the patients.

\section{Therapy of chronic oral GVHD}

Extracorporeal photopheresis (ECP) is an effective immunomodulatory therapy with minimal side effects which alleviates cGVHD in most patients. Its curative effects are explained by immunomodulatory action upon T-regulatory lymphocytes. Recent data suggest that favorable effects of extracorporeal photopheresis (UVA irradiation) upon cGVHD may be also caused by inactivation and apoptosis of peripheral blood neutrophils [30]. Meanwhile, chronic GVHD is often refractory to systemic therapies. Some workers draw attention to intraoral narrow-band ultraviolet B (NB-UVB) irradiation in oral cGVHD delivered as a course of 24 phototherapy sessions, at a single dose of $>50 \mathrm{~mJ} / \mathrm{cm} \mathrm{[31].} \mathrm{Median}$ symptom scores (0-10) for sensitivity, pain, and dryness at baseline/end of therapy were $7.5,3,1$, and $3,1,2$, respectively. In sum, $7 / 11$ patients had improvement and 2/11 worsened. Hence, NB-UVB may be considered a treatment option in refractory oral cGVHD, however, requiring clinical trials with appropriate control groups.

A supplementary topical treatment of oral cGVHD is proposed by means the glucocorticoid inhalers [32]. The authors compared different formulations showing pharmacological superiority of Budesonide for topical application in oral cGVHD. Marked local anti-inflammatory effects of Budesonide are based on its very low absorption through mucosal surfaces, thus increasing the potential role in oral cGVHD management. Moreover, its viscous formulation increases mucosal contact time and provides greater pharmacological effect in mucosal inflammation [33].

Second-line treatment in refractory cGVHD may include low doses of alemtuzumab plus low doses of rituximab as suggested by Gutiérrez-Aguirre et al. [34]. The authors have observed 15 patients who received one cycle of subcutaneous alemtuzumab (10 mg/day/3 days), and intravenous rituximab $100 \mathrm{mg}$ on $\mathrm{D}+4,+11,+18$ and +25 post-transplant (the protocol is under clinical trial). The therapeutic response was measured on Days $+30,+90$ and +365 of the protocol. The main site involved was the oral mucosa $(86.7 \%)$. The overall response to the treatment was $100 \%$ at Day +30 evaluation, i.e., 10 patients had partial remission and 5, complete remission. At D+90 evaluation, 7 (50\%) patients had partial remission, 4 (28\%) had complete remission; 3 (21\%) had relapsed chronic graft-versus-host disease and one patient did not reach the evaluation time point. Adverse effects were mainly infections in $67 \%$ of patients; these were usually quickly solved.

\section{Specific cautions for drug therapy following HSCT}

First of all, one should take into account those anticancer drugs that carry the highest risk for mucositis, i.e., methotrexate, cyclophosphamide, cisplatin, and fluorouracil (Villa, Sonis, 2015).

Risk of mucositis is dose-dependent and increases with higher intensity of chemo- and/or radiation therapy. One should be cautious when administering some drugs to such patients, as follows [10]:

- General anesthetics;

- Non-steroid anti-inflammatory drugs (NSAIDs) since these drugs may augment cyclosporine and tacrolimus nephrotoxicity, and they may increase bleeding and aggravate peptic ulcers in the corticosteroid-treated patients;

- Aspirin dosage should be adjusted since it increases bleeding risks;

- Antibiotics (erythromycin, clarithromycin, tetracycline, aminoglycosides, chinolones), as well as azol antifungal azoles (ketonazol, fluconazole and itroconazol), like as NSAIDs could aaalter cyclosporine lebels in blood serum thus causing more expressed immunosuppression.

- Usage of Sirolimus, and probably, of other mTOR inhibitors for the GVHD prophylaxis, may cause acute ulcerative stomatitis affecting the non-keratinized mucosa, mainly, with tongue involvement, at median onset time of 55 days after HCST [35]. Topical corticosteroid treatment is successful in these cases.

\section{Potential diagnostic markers}

Dozens of salivary components may reflect different diseases of periodont and oral cavity, including inflammatory mediators, reactive oxidative products, cellular enzymes, tissue-breakdown products etc. [36]. Over last decade, a number of reviews have been dedicated to potential clinical significance of salivary markers for diagnostics of different somatic and infectious disorders. E.g., salivary diagnostics of cancer proteins in oral fluid is now an evolving field of diagnostics as reported by Kaur et al. [37]. However, most of current studies are directed to novel applications of salivary using the "omics" approach, studying genomic, transcriptomic, proteomic, microbiomic, and metabolomic parameters, thus bringing the solution to a big data analysis [38]. Meanwhile, a search may be focused on single specific markers showing distinct pathological disorders of oral cavity or in the entire host organism. 


\section{DNA markers}

Salivary biomarkers for infectious diseases were extensively studied earlier [39]. The issue is that the infectious agents were detected by different laboratory tests (by specific antibodies, antigens or nucleic acid markers) in salivary samples. These include a large range of Herpes viruses, Hepatitis viruses, HIV, Human Papillomavirus (HPV), Influenza virus, and Poliovirus.

Moreover, hundreds of bacterial species could be found in saliva, at the oral mucosa, dental plaques and tongue surface including Escherichia coli, Mycobacterium tuberculosis, Helicobacter pylori, Treponema pallidum and a wide range of streptococcal species. Concerning fungal presentation in oral rinses, Candida species were the most frequently cultured fungi (in $75 \%$ of samples), followed by Cladosporium (65\%), Aureobasidium, Saccharomycetales (50\% for both), Aspergillus (35\%), Fusarium (30\%), and Cryptococcus (20\%). [40].

Post-cytostatic immune deficiency is regularly associated with viral infections. In this view, the levels of herpesvirus type VI (HHVVI) in saliva were suggested to be a probable severity marker of chemotherapy-induced oral damage [41]. However, excessive HHV6 activation was not confirmed at later terms post-HSCT, in chronic GVHD patients [42]. The authors tested for HHV6 peripheral blood, different oral fluids from cGVHD patients and oral tissue samples from healthy blood donors. HHV6 was detected by nested polymerase chain reaction. The virus was detected in whole saliva in 13 cGVHD patients $(68 \%)$ and in 19 blood donors (67\%) but not in gingival crevicular fluid or parotid gland saliva. Only two oral tissue samples of cGVHD patients of 12 were positive for HHV6. In sum, these data do not support the importance of HHV6 in oral lesions of cGVHD.

Over 40 years, it has been well known that oral cavity and intestinal microbiota contain similar bacterial species as shown, e.g., by Hamilton et al. [43]. Large numbers of similar organisms $(>106 / \mathrm{m} 1)$ were recovered by microbiological cultures from oral samples and jejunal aspirate of 16 subjects, in five of whom the same organisms were present in similar relative proportions in the saliva, e.g., Fusobacteria, whereas in other cases jejunal organisms differed from those in saliva. In eight of them, jejunal flora showed a typical 'faecal' pattern usually associated with small bowel bacterial overgrowth but, in three, the jejunal floral was somewhat similar to that of saliva.

Nowadays, with development of high-throughput NGS and 16S RNA sequencing, these ratios are studied in more details [44]. Human microbiota from three different compartments, i.e., saliva, feces, and cancer tissue (CT), of patients with colorectal cancer (CRC) vs. 10 healthy controls (saliva and feces). Taxonomic analysis based on 16S rRNA gene, revealed the presence of three main bacterial phyla, which includes about $80 \%$ of sequence reads: Firmicutes, Bacteroidetes, and Proteobacteria. Differences in bacterial composition, F. nucleatum abundance in healthy controls vs. colon cancer patients, and the association of $F$. nucleatum with clinical parameters were observed. Hence, Fusobacterium species are part of the both oral and intestinal microbiota, especially of colon tissue. Metagenomic analyses have shown that $F$. nucleatum detection in saliva may be predictive for development of colorectal cancer (Nosho et al., 2016).

The leukocytes shed to saliva may be also used even for detection of specific mutations in the patients with myeloproliferative diseases. E.g., Strati et al. [45] have performed a comparative study of JAK2 ${ }^{\mathrm{V} 617 \mathrm{~F}}$ mutation in blood and saliva taken from the patients with primary myelofibrosis. Analysis of results from 167 patients has shown that the concordance between JAK2 $2^{\mathrm{V} 617 \mathrm{~F}}$ detection in blood and saliva was $96 \%$, with a sensitivity of $100 \%$ and a specificity of $90 \%$. This biological material seems to have, at least, as sensitive as blood analysis for this mutation.

\section{Protein markers}

Like as DNA markers, immune protein molecules, like specific immunoglobulins, may be measured in saliva and salivary gland secretions in order to detect some latent and activable viruses [46].

Searching novel markers of acute GVHD is an important issue. E.g., one may check such potential salivary biomarkers as S100 protein family members (S100A8, S100A9, and S100A7) performed by Chiusolo et al. [47]. By means of HPLC, the authors have shown S100A8 in 14 of 23 cases of GVHD in allo-HSCT patients as compared with 2 GVHDfree parients and in none case of control group ( $(\mathrm{P}<0.001)$. Similar trend was registered for S100A9 protein. Multiple analysis of salivary proteome allows to detect some candidate proteins specific to acute GVHD as shown by Souza et al. [48] who carried out a preliminary study of salivary proteins using PAGE gel electrophoresis, liquid chromatograpy, and modern mass spectrometry. The most relevant proteins recognized exclusively in GVHD patients were: CSF2RB, protocadherin Fat 2 precursor, protein capicua homolog isoform CIC-S, MUC16 and RGPD8_HUMAN RANBP2. Their physiological role in this complication is not clear and needs further studies.

Diagnostic and prognostic markers of acute or chronic chronic GVHD are currently searched by means of proteomic analysis performed with mass-spectrometry or other methods of protein analysis. For example, saliva collected from oral cavity of allo-HSCT patients with chronic oral GVHD and cGVHD-free cases using isobaric Tags for quantification labeling, followed by tandem mass spectrometry. The method allowed identify up to 249 salivary proteins. Of them, 82 proteins were differently expressed in oral cGVHD patients compared to GVHD-free patients. Of these proteins, most played role in immunity, proteolytic functions, or as cytoskeleton components. Salivary IL-1 receptor antagonist and Cystatin B proved to exhibit decreased expression in oral chronic GVHD $(\mathrm{P}<0.003)$, thus, probably, being of some diagnostic significance [49].

\section{Conclusions}

1. Intensive chemotherapy and radiation treatment of the oncohematological patients followed by hematopoietic stem cell transplantation (HSCT) brings about early inflammation and acute necrosis of oral mucosa and gingivae, atrophy of salivary glands 
2. Immune deficiency is evident at all post-transplant phases and later, at the stage of immunesuppressive therapy. At early terms, it is complicated by infections, at later phase, by autoimmune affection of oral mucosae. Over next years, a risk of secondary cancers is increased.

3. Bacterial and fungal infections of oral cavity and gastrointestinal tract are especially common at early terms, whereas viral activation (including secondary tumors) is detected at later terms after HSCT. The diagnosis of infections in immunocompromised patients represents an important task for the dentist that should be resolved in close contact with attending physician.

4. Late oral pathology after HSCT in children is presented, mainly, by developmental anomalies of dental system in young patients.

5. Chronic graft-versus-host disease (cGVHD) is accompanied by the Sjogren-like problems with oral mucosa and salivary glands.

6. There is no effective etiological treatment for acute mucositis, oral GVHD, both acute and chronic clinical forms. Appropriate pathogenetic therapy is aimed for release of painful symptoms and anti-inflammatory treatment. Some new promising drugs are still used as experimental therapy.

6. By the present time, there are no recognized salivary markers for early diagnostic and prediction of severe damage of oral mucosa expected after intensive cytostatic therapy, as well as GVHD following allogeneic transplantation. However, some promising salivary tests are to be studied, to detect infections of oral cavity, local and systemic malignancies.

\section{Conflict of interest}

No conflict of interest reported.

\section{References}

1. Bobrov A.P., Tkachenko T.B. Changes of oral mucosa in oncological patients in the course of chemotherapy. Stomatologiia. 2006; 85(6):70-73 (In Russian)

2. Elad S., Raber-Durlacher J.E., Brennan M.T., Saunders D.P., Mank A.P., Zadik Y., et al. Basic oral care for hematology-oncology patients and hematopoietic stem cell transplantation recipients: a position paper from the joint task force of the Multinational Association of Supportive Care in Cancer/ International Society of Oral Oncology (MASCC/ISOO) and the European Society for Blood and Marrow Transplantation (EBMT). Support Care Cancer. 2015; 23(1):223-236.

3. Wong H.M. Oral complications and management strategies for patients undergoing cancer therapy. ScientificWorldJournal. 2014, Jan 8;2014:581795.

4. Umarova K.V. Combined treatment of mucositis induced by chemo- and radiotherapy in the patients with oncological diseases of oral organs and tissues. Stomatologiia. 2017; 3:6364. (In Russian)
5. Pankratova O.S., Chukhlovin A.B. Time course of immune recovery and viral reactivation following hematopoietic stem cell transplantation. Cell Ther Transplant. 2016; 5(4): 32-43.

6. Guideline on dental management of pediatric patients receiving chemotherapy, hematopoietic cell transplantation, and/or radiation therapy. Reference Manual, American Academy of Pediatric Dentistry, 2013; 37(6): 298-306.

7. Marty F.M., Rubin R.H. The prevention of infection post-transplant: the role of prophylaxis, preemptive and empiric therapy. 2005, Transplant International, 2005; 19:2-11.

8. Chukhlovin A.B., Pankratova O.S. Opportunistic microflora at unusual sites: marker pathogens in severe posttransplant immune deficiency. Cell Ther Transplant. 2017; 6(4): 28-41.

9. Haverman T.M., Raber-Durlacher J.E., Rademacher W.M., Vokurka S., Epstein J.B., Huisman C. Oral complications in hematopoietic stem cell recipients: the role of inflammation. Mediators Inflamm. 2014;2014:378281.

10. Fabuel L.C., Esteve C.G., Pérez G.S. Dental management in transplant patients. J Clin Exp Dent. 2011;3(1):e43-52.

11. Pankratova O.S., Chukhlovin A.B., Shiryaev S.N., Eismont Y.A., Vavilov V.N., Zubarovskaya L.S., Afanasyev B.V. Herpesviruses and oral ulcerations in hematopoietic SCT recipients. Bone Marrow Transplant. 2013; 48(10):1364-1365.

12. Chaudhry HM, Bruce AJ, Wolf RC, Litzow MR, Hogan WJ, Patnaik MS, Kremers WK, Phillips GL, Hashmi SK. The incidence and severity of oral mucositis among allogeneic hematopoietic stem cell transplantation patients: a systematic review. Biol Blood Marrow Transplant. 2016;22(4):605616.

13. Kolbinson DA, Schubert MM, Flournoy N, Truelove EL. Early oral changes following bone marrow transplantation. Oral Surg Oral Med Oral Pathol. 1988;66(1):130-138.

14. Dahllöf G, Heimdahl A, Modéer T, Twetman S, Bolme $\mathrm{P}$, Ringdén $\mathrm{O}$. Oral mucous membrane lesions in children treated with bone marrow transplantation. Scand J Dent Res. 1989; 97(3):268-277.

15. Solov'eva A.M., Matelo S.K., Totolian A.A., Chukhlovin A.B., Konstantinova V.E., Kobiiasova I.V., et al. Epidemiological study of the prevalence in periodontal pathogenic microflorae of oral cavity in the population of Russia. Stomatologiia. 2005;84(5):14-20. (In Russian)

16. Allareddy V., Venugopalan S.R., Eswaran S.V.K., Rampa S., Anamali S., Nalliah R.P., et al. Important impact of gingival and periodontal conditions on outcomes in SCT recipients. Bone Marrow Transplantation. 2015;50:604-606.

17. Kadakia MP, Rybka WB, Stewart JA, Patton JL, Stamey FR, Elsawy M, Pellett PE, Armstrong JA. Human herpesvirus 6: infection and disease following autologous and allogeneic bone marrow transplantation. Blood. 1996;87(12):53415354 . 
18. Cone RW, Huang ML, Corey L, Zeh J, Ashley R, Bowden. Human herpesvirus 6 infections after bone marrow transplantation: clinical and virologic manifestations. J Infect Dis. 1999;179(2):311-318.

19. Motta A, Zhan Q, Larson A, Lerman M, Woo SB, Soiffer RJ, Murphy GF, Treister NS. Immunohistopathological characterization and the impact of topical immunomodulatory therapy in oral chronic graft-versus-host disease: A pilot study. Oral Dis. 2018;24(4):580-590.

20. Mays J.W., Fassil H., Edwards D.A., Pavletic S.Z., Bassim C.W. Oral chronic graft-versus-host disease: current pathogenesis, therapy, and research. Oral Dis. 2013;19(4):327-346.

21. Fassil H., Bassim C.W., Mays J., Edwards D., Baird K., Steinberg S.M., et al. Oral chronic graft-vs.-host disease characterization using the NIH scale. Journal of Dental Research. 2012;91:S45-S51.

22. Rozmus J., Schultz K.R. Biomarkers in chronic graft-versus-host disease. Expert Rev Hematol. 2011;4(3):329-342.

23. Villa A, Sonis ST. Pharmacotherapy for the management of cancer regimen-related oral mucositis. Expert Opin Pharmacother. 2016;17(13):1801-1807. doi: $10.1080 / 14656566.2016 .1217993$

24. Spielberger R, Stiff P, Bensinger W, et al. Palifermin for oral mucositis after intensive therapy for hematologic cancers. N Engl J Med. 2004;351(25):2590-2598.

25. Piccin A, Rebulla P, Pupella S, Tagnin M, Marano G, Di Pierro AM, Santodirocco M, Di Mauro L, Beqiri L, Kob M, Primerano M, Casini M, Billio A, Eisendle K, Fontanella F. Impressive tissue regeneration of severe oral mucositis post stem cell transplantation using cord blood platelet gel. Transfusion. 2017;57(9):2220-2224. doi: 10.1111/trf.14205.

26. Eduardo Fde P, Bezinelli LM, de Carvalho DL, Lopes RM, Fernandes JF, Brumatti M, Vince CS, de Azambuja AM, Vogel C, Hamerschlak N, Correa L. Oral mucositis in pediatric patients undergoing hematopoietic stem cell transplantation: clinical outcomes in a context of specialized oral care using low-level laser therapy. Pediatr Transplant. 2015;19(3):316325. doi:10.1111/petr.12440.

27. Ion D, Stevenson K, Woo SB, Ho VT, Soiffer R, Antin JH, Treister NS. Characterization of oral involvement in acute graft-versus-host disease. Biol Blood Marrow Transplant. 2014; 20(11):1717-1721. doi: 10.1016/j.bbmt.2014.06.031.

28. Picardi A, Lanti A, Cudillo L, Cerretti R, Dentamaro T, De Angelis G, Ferraro A, Di Veroli A, Adorno G, Arcese W; Rome Transplant Network. Platelet gel for treatment of mucocutaneous lesions related to graft-versus-host disease after allogeneic hematopoietic stem cell transplant. Transfusion. 2010;50(2):501-506. doi: 10.1111/j.1537-2995.2009.02439.x.

29. Steinbach G, Hockenbery DM, Huls G, Furlong T, Myerson D, Loeb KR, Fann JR, Castilla-Llorente C, McDonald GB, Martin PJ. Pilot study of lithium to restore intestinal barrier function in severe graft-versus-host disease. PLoS One. 2017;12(8):e0183284. doi: 10.1371/journal.pone.0183284.
30. Franklin C, Cesko E, Hillen U, Schilling B, Brandau S. Modulation and Apoptosis of Neutrophil Granulocytes by Extracorporeal Photopheresis in the Treatment of Chronic Graft-Versus-Host Disease. PLoS One. 2015;10(8):e0134518. doi: 10.1371/journal.pone.0134518.

31. Treister N, Li S, Lerman MA, Lee S, Soiffer R. Narrow-band UVB phototherapy for management of oral chronic graft-versus-host disease. Photodermatol Photoimmunol Photomed. 2015;31(2):75-82.

32. Zadik Y, Elad S, Shapira A, Shapira MY. Treatment of oral mucosal manifestations of chronic graft-versus-host disease: dexamethasone vs. budesonide. Expert Opin Pharmacother. 2017;18(3):235-242.

33. Bertelli L, Di Nardo G, Zama D, Bardasi G, Morello W, Masetti R, Belotti T, Forchielli ML, Prete A, Pession A. A New Formulation of an Old Drug: A Potential New Therapy in the Management of Oral cGvHD. J Pediatr Hematol Oncol. 2016;38(8):e295-e297.

34. Gutiérrez-Aguirre $\mathrm{CH}$, Cantú-Rodríguez OG, Borjas-Almaguer OD, González-Llano O, Jaime-Pérez JC, Solano-Genesta M, Gómez-Guijosa M, Mancias-Guerra C, Tarin L, Gómez-Almaguer D. Effectiveness of subcutaneous low-dose alemtuzumab and rituximab combination therapy for steroid-resistant chronic graft-versus-host disease. Haematologica. 2012; 97(5):717-722.

35. Villa A, Aboalela A, Luskin KA, Cutler CS, Sonis ST, Woo SB, Peterson DE, Treister NS. Mammalian target of rapamycin inhibitor-associated stomatitis in hematopoietic stem cell transplantation patients receiving sirolimus prophylaxis for graft-versus-host disease. Biol Blood Marrow Transplant. 2015;21(3):503-508.

36. Ghallab N.A. Diagnostic potential and future directions of biomarkers in gingival crevicular fluid and saliva of periodontal diseases: Review of the current evidence. Arch Oral Biol. 2018;87:115-124.

37. Kaur J, Jacobs R, Huang Y, Salvo N, Politis C. Salivary biomarkers for oral cancer and pre-cancer screening: a review. Clin Oral Investig. 2018;22(2):633-640.

38. Hassaneen M, Maron JL. Salivary Diagnostics in Pediatrics: Applicability, Translatability, and Limitations. Front Public Health. 2017;5:83. doi: 10.3389/fpubh.2017.00083.

39. Malamud D., Rodriguez-Chavez IR. Saliva as a diagnostic fluid. Dent Clin North Am. 2011; 55(1): 159-178.

40. Ghannoum MA, Jurevic RJ, Mukherjee PK, Fan Cui, Sikaroodi M, Naqvi A, Gillevet PM. Characterization of the oral fungal microbiome (mycobiome) in healthy individuals. PLoS Pathog. 2010;6(1):e1000713.

41. Ito T, Urushima H, Sakaue M, Yukawa S, Honda H, Hirai K, Igura T, Hayashi N, Maeda K, Kaste S.C., Hopkins K.P., Jones D., Crom D., Greenwald C.A., Santana V.M. Dental abnormalities in children treated for acute lymphoblastic leukemia. Leukemia. 1997; 11:792-796. 
42. Pereira CM, de Almeida OP, Corrêa ME, Costa FF, de Souza CA, Barjas-Castro ML. Detection of human herpesvirus 6 in patients with oral chronic graft-vs-host disease following allogeneic progenitor cell transplantation. Oral Dis. 2007;13(3):329-334.

43. Hamilton I, Worsley BW, Cobden I, Cooke EM, Shoesmith JG, Axon AT. Simultaneous culture of saliva and jejunal aspirate in the investigation of small bowel bacterial overgrowth. Gut. 1982;23(10):847-853.

44. Russo E, Bacci G, Chiellini C, Fagorzi C, Niccolai E, Taddei A, Ricci F, Ringressi MN, Borrelli R, Melli F, Miloeva M, Bechi P, Mengoni A, Fani R, Amedei A. Preliminary comparison of oral and intestinal human microbiota in patients with colorectal cancer: a pilot study. Front Microbiol. 2018; 8:2699. doi: 10.3389/fmicb.2017.02699

45. Strati P, Benton CB, Manshouri T, Zhang Y, Bove JE 4th, Sanchez-Petitto G, Verstovsek S. JAK2 ${ }^{\mathrm{V} 617 \mathrm{~F}}$ detection and allele burden measurement in saliva vs. peripheral blood in patients with myelofibrosis. Leuk Res. 2017;63:53-55.

46. Corstjens PL, Abrams WR, Malamud D. Detecting viruses by using salivary diagnostics. J Am Dent Assoc. 2012;143(10 Suppl):12S-8S.
47. Chiusolo P, Giammarco S, Fanali C, Bellesi S, Metafuni E, Sica S, Iavarone F, Cabras T, Messana I, Leone G, Castagnola M. Salivary proteomic analysis and acute graft-versus-host disease after allogeneic hematopoietic stem cell transplantation. Biol Blood Marrow Transplant 2013; 19: 888-892.

48. Souza MM, de Paula FM, Hsieh R, Macedo MC, Corral MA, Nunes TB, De Paula F, Lourenço SV. Could mucin 16 and colony-stimulating factor 2-receptor beta possible graft-versus-host-disease biomarkers? Med Hypotheses. 2017;100:89-93.

49. Devic I, Shi M, Schubert MM, Lloid M, Izutsu KT, Pan C, Missaghi M, Morton TH, Mancl LA, Zhang J, Presland RB. Proteomic analysis of saliva from patients with oral chronic graft-versus-host disease. Biol Blood Marrow Transplant. 2014;20(7):1048-1055.

50. Javaid MA, Ahmed AS, Durand R, Tran SD, Saliva as a diagnostic tool for oral and systemic diseases. J Oral Biol Craniofac Res. 2016;6:66-75.

\title{
Стоматологические проблемы и инфекционные осложнения после трансплантации гемопоэтических стволовых клеток
}

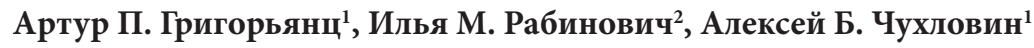 \\ ${ }^{1}$ Первый Санкт-Петербургский государственный медицинский университет им. И. Павлова, Санкт-Петербург, Россия \\ ${ }^{2} Ц$ ценральный научно-исследовательский институт стоматологии, Москва, Россия
}

\section{Резюме}

Данная обзорная статья описывает ранние и поздние стоматологические осложнения, возникающие после интенсивной антибластомной химио- и радиотерапии и трансплантации гемопоэтических стволовых клеток (ТГСК). Высокодозная циторедуктивная терапия может сопровождаться долгосрочными цитопениями с медленным восстановлением миелои лимфопоэза, осложнениями иммуносупрессивного лечения в связи с «болезнью трансплантат против хозяина» (РТПХ). Таким образом, эта иммунная патология сопряжена с высоким риском стоматологических инфекций, что требует профилактического лечения кариеса и антисептической обработки в периоде цитопении. Связанное с терапией повреждение эпителия ротовой полости ведет к развитию раннего мукозита и отягощает течение острой реакции «трансплантат против хозяина». Аутоиммуноподобные осложнения (атрофия эпителия полости рта и слюнных желез, синдром «сухого рта») часто отмечаются в течение нескольких месяцев после аллогенной ТГСК. У пациентов детского возраста массивная химио- и лучевая терапия дают осложнения в виде задержки развития корней зубов, задержка прорезывания зубов, гипоплазия зубной эмали и др. У взрослых цитостатическая химиотерапия ведет к более интенсивной патологии пародонта. Предложены дифференциальные протоколы для детей и взрослых с целью профилактики и лечения зубной патологии у пациентов после ауто- или алло-ТГСК.

\section{Ключевые слова}

Трансплантация гемопоэтических стволовых кле ток, цитостатическая терапия, иммуносупрессивное лечение, эпителий полости рта, иммуно-опосредованные заболевания, инфекции зубов, лечение, профилактика. 